\title{
VARIABILIDAde No GRAU de Resistência de CAPIM-MaRmelada (Brachiaria plantaginea) AOS HERBICIDAs ClethodIM, TEPRALOXYDIM E SETHOXYDIM ${ }^{1}$
}

\author{
Variability in the Degree of Resistance of Alexandergrass (Brachiaria plantaginea) to the \\ Herbicides Clethodim, Tepraloxydim, and Sethoxydim
}

GAZZIERO, D.L.P. ${ }^{2}$, BRIGHENTI, A.M. ${ }^{2}$, VOLL, E. ${ }^{2}$, PRETE, C.E.C. ${ }^{2}$, SUMIYA, M. ${ }^{2}$ e KAJIHARA, L. ${ }^{2}$

\begin{abstract}
RESUMO - O uso continuado de herbicidas pertencentes a um único mecanismo de ação resulta em pressão de seleção de biótipos resistentes de plantas daninhas. No Brasil, as primeiras manifestações de resistência foram relatadas com as espécies de capim-marmelada (Brachiaria plantaginea), picão-preto (Bidens spp.) e amendoim-bravo (Euphorbia heterophylla). Tem-se verificado que, quando da ocorrência da resistência de uma planta daninha a um determinado produto, o problema se estende aos demais produtos que possuem o mesmo mecanismo de ação. Sabe-se, porém, que o grau de resistência poderá variar entre os produtos e, eventualmente, ocorrer resistência para uns e não para outros. Com o objetivo de avaliar possiveis diferenças na eficiência de produtos inibidores da enzima ACCase em biótipos resistentes de capim-marmelada, foram conduzidos dois experimentos em casa de vegetação em Londrina-PR. Os tratamentos incluíram os herbicidas sethoxydim, clethodim e tepraloxydim, em diferentes doses. No primeiro, as aplicações foram realizadas com as plantas no estádio de um a dois afilhos e, no segundo, no estádio de dois a três afilhos. Embora os três compostos químicos atuem na inibição da enzima ACCase, foi evidenciada elevada diferença no grau de resistência do capim-marmelada a esses produtos. Os resultados indicaram que o biótipo considerado resistente ao herbicida sethoxydim foi suscetivel aos produtos clethodim e tepraloxydim.
\end{abstract}

Palavras-chave: capim-papuã, soja, gramíneas.

\begin{abstract}
The continuous use of herbicides with a single mechanism of action results in selection pressure of resistant weed biotypes. In Brazil, the first manifestations of resistance occurred with Alexandergrass species (Brachiaria plantaginea), beggarticks (Bidens spp.) and wild poinsettia (Euphorbia heterophylla). The occurrence of weed resistance to a particular product has been found to extend to other products with the same mechanism of action. It is known, however, that the degree of resistance can vary among products and ultimately resistance may occur only to some compounds. Two experiments were carried out under glasshouse conditions in Londrina-Parana to evaluate possible differences in the efficiency of ACCase-inhibiting herbicides in resistant Alexandergrass biotypes. Treatments included the herbicides sethoxydim, clethodim and tepraloxydim at different doses. In the first experiment, the herbicides were applied on plants at 1-to-2 tyller (checar este termo!) growth stage and in the second experiment, on plants at 2-to-3 tyller (checar este termo!) growth stage. Although the three herbicides act as ACCase-inhibitors, a great difference was observed in the degree of resistance of Alexandergrass to these products. Results indicated that the biotype considered resistant to sethoxydim was susceptible to clethodim and tepraloxydim.
\end{abstract}

Key words: Alexandergrass, soybean, grass.

1 Recebido para publicação em 12.11.2002 e na forma revisada em 10.9.2004.

2 Eng.-Agr., Pesquisador do Projeto de Cooperação Institucional, Caixa Postal 231, 86001-970 Londrina-PR, <gazziero@cnpso.embrapa.br>. 


\section{INTRODUÇÃO}

Desde a introdução da soja no Brasil, o capim-marmelada (Brachiaria plantaginea) tem sido considerado uma das principais invasoras dessa cultura. A necessidade do controle das plantas daninhas faz do método químico o mais utilizado pelos agricultores para solucionar problemas de soja, milho, trigo, citros, café e cana. Com o lançamento dos graminicidas de aplicação em pós-emergência das plantas daninhas, os sojicultores passaram a utilizálos intensivamente. O primeiro herbicida lançado foi o diclofop, seguido por sethoxydim, que, dadas as suas características e seu grau de eficiência, foi aplicado anualmente nas mesmas áreas, ano após ano. Com o decorrer do tempo outros produtos foram lançados no mercado. Os graminicidas utilizados em soja pertencem basicamente a dois grupos químicos: os cicloexanodionas (CHD ou DIMS) e os ariloxifenoxiproprionatos (AFP ou FOP). Esses compostos atuam na sintese de lipídios, sendo o mecanismo de ação definido como inibidores da enzima acetil coenzima A carboxilase (ACCase) (SBCPD, 2000).

O uso continuado de herbicidas pertencentes a um único mecanismo de ação resulta em pressão de seleção para biótipos resistentes (Sociedade Brasileira da Ciência das Plantas Daninhas, 2000).

O fenômeno da resistência é conhecido desde os anos 60. Ganhou importância nos anos $70 \mathrm{com}$ as triazinas e nos anos $80 \mathrm{com}$ os inibidores da enzima acetolactatosintase (ALS) e da enzima acetil coenzima A carboxilase (ACCase). Em revisão bibliográfica, Cortez (2000) relata os trabalhos sobre as primeiras referências de plantas resistentes aos CHD e APP, cuja manifestação ocorreu após 7 a 10 anos da introdução desses herbicidas no mercado. Esse autor afirma que quatro anos é suficiente para originar casos de populações resistentes, embora em muitos casos a manifestação ocorra com o dobro desse tempo. Atualmente, no mundo, existe registro de pelo menos 172 espécies que apresentam biótipos resistentes a esses produtos (Weed Science Society of América, 2004).

No Brasil, as primeiras manifestações de resistência foram citadas por Ponchio et al. (1996) e Christoffoleti et al. (1996), para os biótipos de picão-preto, e Gazziero et al. (1998), para biótipos de amendoim-bravo. Para o capim-marmelada, os casos foram relatados por Gazziero et al. (1997) e Vidal \& Fleck (1997), nos Estados do Paraná e Rio Grande do Sul, respectivamente.

Tem sido comum verificar que, quando da ocorrência da manifestação da resistência de uma planta daninha a um determinado produto, o problema se estende aos demais produtos que possuem o mesmo mecanismo de ação. Observações de campo em áreas comerciais de produção têm mostrado que o nível da resistência poderá variar com o produto ou até mesmo que, para certos produtos, a resistência pode não se manifestar. Um estudo foi conduzido em Londrina-PR, com o objetivo de analisar a variabilidade na resistência de biótipos de capim-marmelada a herbicidas inibidores da ACCase.

\section{MATERIAL E MÉTODOS}

Foram conduzidos dois experimentos em casa de vegetação em Londrina-PR, utilizandose vasos com plantas de biótipos suscetíveis e resistentes, registrados como BRAPL-1.02, proveniente de Ponta Grossa, região sul do Estado do Paraná. As sementes do biótipo considerado como resistente foram colhidas em um campo de produção no qual durante muitos anos foram usados produtos inibidores da enzima ACCase, cuja eficiência nas últimas safras deixava a desejar. As sementes do biótipo considerado como suscetivel eram provenientes de um local não-agricultural, próximo ao campo de produção. Foram mantidas três plantas de cada biótipo por vaso, cuja capacidade era de 3 litros de terra preparada com 20\% de matéria orgânica (esterco curtido), 25\% de areia lavada e $55 \%$ de solo comum, previamente esterilizado com brometo de metila.

O delineamento experimental utilizado foi o de blocos ao acaso, com quatro repetições. Os tratamentos são apresentados na Tabela 1 e foram compostos pelos herbicidas clethodim, tepraloxydim e sethoxydim, em diferentes doses, tendo como referência a dose recomendada (Embrapa Soja, 2004).

As aplicações foram feitas com pulverizador costal pressurizado com $\mathrm{CO}_{2}$, com barra de dois bicos 110.015 e volume de calda 
Tabela 1 - Produtos e doses utilizados nos experimentos sobre variabilidade no grau de resistência de capim-marmelada aos herbicidas inibidores da enzima ACCase. Embrapa Soja, Londrina-PR, 2002

\begin{tabular}{|c|c|c|c|c|}
\hline \multicolumn{2}{|c|}{ Tratamento } & \multicolumn{2}{|c|}{ Dose ha $^{-1}$} & \multirow{2}{*}{ Proporção } \\
\hline № Prod. Comercial & Nome comum & gi.a. & L p.c. & \\
\hline 1. Select + Lanzar & clethodim + Lanzar & $60+1,0$ & $0,25+1,0$ & $1 / 2 n^{1 /}$ \\
\hline 2. Select + Lanzar & clethodim + Lanzar & $120+1,0$ & $0,50+1,0$ & $n$ \\
\hline 3. Select + Lanzar & clethodim + Lanzar & $180+1,0$ & $0,75+1,0$ & $11 / 2 n$ \\
\hline 4. Select + Lanzar & clethodim + Lanzar & $240+1,0$ & $1,0+1,0$ & $2 n$ \\
\hline 5. Aramo + Dash & tepraloxydim +Dash & $80+1,0$ & $0,4+1,0$ & $1 / 2 n$ \\
\hline 6. Aramo + Dash & tepraloxydim +Dash & $160+1,0$ & $0,8+1,0$ & n \\
\hline 7. Aramo + Dash & tepraloxydim +Dash & $240+1,0$ & $1,2+1,0$ & $11 / 2 \mathrm{n}$ \\
\hline 8. Aramo + Dash & tepraloxydim +Dash & $320+1,0$ & $1,6+1,0$ & $2 n$ \\
\hline 9. Poast + Assist & sethoxydim + Assist & $230+1,0$ & $1,25+1,0$ & $n$ \\
\hline 10. Poast ${ }^{2}+$ Assist & sethoxydim + Assist & $460+1,0$ & $2,5+1,0$ & $2 n^{2 !}$ \\
\hline 10. Poast ${ }^{3}+$ Assist & sethoxydim + Assist & $920+1,0$ & $5,0+1,0$ & $4 n^{3 /}$ \\
\hline 11. Testemunha & - & - & - & - \\
\hline
\end{tabular}

${ }^{1} / \mathrm{n}=$ dose recomendada no controle de capim-marmelada para aplicação em condições de área comercial; ${ }^{2 /}$ tratamento com sethoxydim utilizado no experimento $1 ; \mathrm{e}^{\underline{3} /}$ tratamento com sethoxydim utilizado no experimento 2 .

equivalente a $150 \mathrm{~L} \mathrm{ha}^{-1}$. No primeiro experimento, as plantas permaneceram em casa de vegetação durante todo o tempo, na qual a temperatura era variável entre 25 e $30{ }^{\circ} \mathrm{C}$, com irrigação programada por gotejamento. Por ocasião da aplicação elas estavam com cerca de $15 \mathrm{~cm}$ de altura e um a dois afilhos (predominando um afilho). No segundo, as plantas estavam com cerca de 10 a $12 \mathrm{~cm}$ de altura e dois a três afilhos (predominando dois afilhos). Neste caso, após a emergência da invasora, os vasos foram mantidos em ambiente externo, com irrigação diária por gotejamento.

Foi avaliado visualmente o controle aos $7 / 18$ e 8/15 após a aplicação dos tratamentos, respectivamente no primeiro e segundo experimentos. A escala adotada foi a percentual, em que zero significou nenhum controle e $100 \%$ controle total. Depois da última avaliação foi determinada a biomassa seca de cada vaso e estabelecida a média por tratamento. Os dados obtidos foram submetidos à análise de variância e ao teste de Tukey a $5 \%$ de probabilidade.

\section{RESULTADOS E DISCUSSÃO}

Os efeitos da ação dos herbicidas sobre as plantas de capim-marmelada, no primeiro experimento, foram observados já aos sete dias após a aplicação. Nas plantas suscetíveis, o nível de controle variou de 88 a 95\%, nas doses recomendadas. Mesmo com a metade dessa dose houve elevado nível de controle com os produtos clethodim e tepraloxydim. Já para as plantas consideradas resistentes a esses herbicidas, o controle foi apenas mediano na dose recomendada (120 g i.a. ha ${ }^{-1}$ de clethodim e 160 g i.a. ha-1 de tepraloxydim), enquanto para sethoxydim o controle foi considerado insatisfatório, mesmo com quatro vezes a dose recomendada de 230 g i.a. ha ${ }^{-1}$ (Tabela 2).

Aos 18 dias da aplicação, as plantas suscetíveis foram consideradas totalmente controladas com os três produtos, não tendo sido encontradas diferenças significativas entre estes. Nas plantas tidas como resistentes verificou-se controle daquelas tratadas com clethodim e tepraloxydim e recuperação das que foram submetidas ao sethoxydim (Tabela 2). A biomassa seca refletiu a avaliação visual, indicando não haver diferenças significativas entre os produtos clethodim e tepraloxydim. Entretanto, para o sethoxydim na dose normal, o peso da biomassa seca das plantas foi semelhante ao encontrado na testemunha não-aplicada (Tabela 4).

Gazziero et al. (2000) conduziram experimentos em Londrina-PR e Piracicaba-SP com o biótipo de capim-marmelada registrado como 
B-1.96, com suspeita de resistência. O material proveniente de Mangueirinha, sudoeste do Paraná, foi avaliado utilizando herbicidas dos grupos químicos CHD e AFP, em doses que variaram de metade até oito vezes a dose recomendada para cada produto. Nos dois locais, os resultados com o clethodim mostraram-se semelhantes aos encontrados neste trabalho, enquanto para os demais produtos foi confirmada a resistência.

Tabela 2 - Comportamento de herbicidas graminicidas aplicados em pós-emergência sobre capim-marmelada (Brachiaria plantaginea), biótipos resistentes (R) e suscetíveis (S). Experimento 1. Embrapa Soja, Londrina-PR, 2002

\begin{tabular}{|c|c|c|c|c|c|}
\hline \multirow{3}{*}{ Tratamento } & \multirow{3}{*}{$\begin{array}{c}\text { Dose } \\
\text { (Proporção) }\end{array}$} & \multicolumn{4}{|c|}{ Controle $(\%)$} \\
\hline & & \multicolumn{2}{|c|}{$7 \mathrm{DAA}^{1 / 1}$} & \multicolumn{2}{|c|}{$18 \mathrm{DAA}$} \\
\hline & & $\mathrm{S}$ & $\mathrm{R}$ & $\mathrm{S}$ & $\mathrm{R}$ \\
\hline Clethodim & $1 / 2 \mathrm{n}^{2 /}$ & $90,0 \mathrm{bcd}^{3 /}$ & $65,0 \mathrm{c}$ & 99,5 & $90,0 \mathrm{~b}$ \\
\hline Clethodim & $\mathrm{n}$ & $87,5 \mathrm{~d}$ & $68,8 \mathrm{c}$ & 100,0 & $97,0 \mathrm{a}$ \\
\hline Clethodim & $11 / 2 n$ & $95,0 \mathrm{abcd}$ & $82,5 \mathrm{a}$ & 100,0 & $99,5 \mathrm{a}$ \\
\hline Clethodim & $2 n$ & $97,5 \mathrm{abc}$ & $90,0 \mathrm{a}$ & 100,0 & $100,0 \mathrm{a}$ \\
\hline Tepraloxydim & $1 / 2 n$ & $86,3 \mathrm{~d}$ & $50,0 \mathrm{~d}$ & 99,5 & $91,3 \mathrm{~b}$ \\
\hline Tepraloxydim & $n$ & $95,0 \mathrm{abcd}$ & $66,3 \mathrm{c}$ & 100,0 & $98,3 \mathrm{a}$ \\
\hline Tepraloxydim & $11 / 2 n$ & $100,0 \mathrm{a}$ & $70,0 \mathrm{bc}$ & 100,0 & $99,5 \mathrm{a}$ \\
\hline Tepraloxydim & $2 n$ & $98,8 \mathrm{ab}$ & $81,3 \mathrm{ab}$ & 100,0 & $100,0 \mathrm{a}$ \\
\hline Sethoxydim & $n$ & $88,8 \mathrm{~cd}$ & $21,3 \mathrm{e}$ & 100,0 & $0,0 \mathrm{c}$ \\
\hline Sethoxydim & $2 n$ & $95,0 \mathrm{abcd}$ & $26,3 \mathrm{e}$ & 100,0 & $0,0 \mathrm{c}$ \\
\hline Testemunha & - & $0,0 \mathrm{e}$ & $0,0 \mathrm{f}$ & 0,0 & $0,0 \mathrm{c}$ \\
\hline $\mathrm{F}$ & & 6,91 & 85,62 & n.s & $3.354,04$ \\
\hline $\mathrm{CV}$ & & 3,98 & 8,03 & - & 1,82 \\
\hline DMS 5\% & & 9,06 & 12,14 & - & 3,44 \\
\hline
\end{tabular}

${ }^{1 /}$ DAA = dias após aplicação; ${ }^{2 /} \mathrm{n}=$ dose recomendada no controle de capim-marmelada para aplicação em condições de área comercial;

${ }^{3 /}$ médias seguidas da mesma letra na coluna não diferem entre si a $5 \%$ pelo teste de Tukey.

Tabela 3 - Comportamento de herbicidas graminicidas aplicados em pós-emergência sobre capim-marmelada (Brachiaria plantaginea), biótipos resistentes (R) e suscetíveis (S). Experimento 2. Embrapa Soja, Londrina-PR, 2002

\begin{tabular}{|c|c|c|c|c|c|}
\hline \multirow{3}{*}{ Tratamento } & \multirow{3}{*}{$\begin{array}{c}\text { Dose } \\
\text { (Proporção) }\end{array}$} & \multicolumn{4}{|c|}{ Controle $(\%)$} \\
\hline & & \multicolumn{2}{|c|}{$8 \mathrm{DAA}^{1 / 1}$} & \multicolumn{2}{|c|}{$15 \mathrm{DAA}$} \\
\hline & & $S$ & $\mathrm{R}$ & $\mathrm{S}$ & $\mathrm{R}$ \\
\hline Clethodim & $1 / 2 \mathrm{n}^{2 /}$ & 99,75 & $89,0 b^{3}$ & 100,0 & $96,0 \mathrm{~b}$ \\
\hline Clethodim & n & 100,0 & $95,75 \mathrm{ab}$ & 100,0 & $99,5 \mathrm{a}$ \\
\hline Clethodim & $11 / 2 n$ & 100,0 & $98,75 \mathrm{a}$ & 100,0 & $100,0 \mathrm{a}$ \\
\hline Clethodim & $2 n$ & 100,0 & $97,25 \mathrm{a}$ & 100,0 & $100,0 \mathrm{a}$ \\
\hline Tepraloxydim & $1 / 2 n$ & 97,5 & $81,25 \mathrm{~d}$ & 99,75 & $88,5 \mathrm{c}$ \\
\hline Tepraloxydim & $n$ & 100,0 & $85,75 \mathrm{~cd}$ & 100,0 & $96,0 \mathrm{~b}$ \\
\hline Tepraloxydim & $11 / 2 n$ & 99,75 & $92,5 \mathrm{abc}$ & 100,0 & $98,25 \mathrm{ab}$ \\
\hline Tepraloxydim & $2 n$ & 100,0 & $94,75 \mathrm{ab}$ & 100,0 & $99,25 \mathrm{a}$ \\
\hline Sethoxydim & n & 97,5 & $10,0 \mathrm{f}$ & 99,75 & $0,0 \mathrm{e}$ \\
\hline Sethoxydim & $2 n$ & 100,0 & $37,5 \mathrm{e}$ & 100,0 & $13,75 \mathrm{~d}$ \\
\hline Testemunha & - & 0,0 & $0,0 \mathrm{f}$ & 0,0 & $0,0 \mathrm{e}$ \\
\hline $\mathrm{F}$ & & n.s. & 425,823 & n.s. & $5.269,076$ \\
\hline $\mathrm{CV}$ & & - & 3,70 & - & 1,33 \\
\hline DMS 5\% & & - & 7,063 & - & 2,574 \\
\hline
\end{tabular}

${ }^{1} /$ DAA = dias após aplicação; ${ }^{2} / \mathrm{n}=$ dose recomendada no controle de capim-marmelada para aplicação em condições de área comercial; ${ }^{3 /}$ médias seguidas da mesma letra na coluna não diferem entre si a $5 \%$ pelo teste de Tukey. 
Tabela 4 - Biomassa seca obtida nos experimentos sobre a variabilidade na resistência de capim-marmelada aos herbicidas clethodim, tepraloxydim e sethoxydim. Embrapa Soja, Londrina-PR, 2002

\begin{tabular}{|c|c|c|c|c|c|c|c|}
\hline \multirow{2}{*}{\multicolumn{2}{|c|}{ Tratamento }} & \multirow{2}{*}{\multicolumn{2}{|c|}{ Dose ha ${ }^{-1}$}} & \multicolumn{4}{|c|}{ Biomassa seca $(\mathrm{g})$} \\
\hline & & & & \multicolumn{2}{|c|}{ Experimento 1} & \multicolumn{2}{|c|}{ Experimento 2} \\
\hline Prod. Comercial & Nome comum & g i.a. & L-p.c. & $\mathrm{S}$ & $\mathrm{R}$ & $\mathrm{S}$ & $\mathrm{R}$ \\
\hline Select + Lanzar & clethodim + Lanzar & $60+1,0$ & $0,25+1,0$ & $0,33 b^{-1 /}$ & $1,00 \mathrm{~b}$ & $0,40 \mathrm{~b}$ & $0,48 \mathrm{c}$ \\
\hline Select + Lanzar & clethodim + Lanzar & $120+1,0$ & $0,50+1,0$ & $0,42 \mathrm{~b}$ & $0,78 \mathrm{~b}$ & $0,46 \mathrm{~b}$ & $0,52 \mathrm{c}$ \\
\hline Select + Lanzar & clethodim + Lanzar & $180+1,0$ & $0,75+1,0$ & $0,30 \mathrm{~b}$ & $0,58 \mathrm{~b}$ & $0,41 \mathrm{~b}$ & $0,70 \mathrm{c}$ \\
\hline Select + Lanzar & clethodim + Lanzar & $240+1,0$ & $1,0+1,0$ & $0,42 \mathrm{~b}$ & $0,57 \mathrm{~b}$ & $0,50 \mathrm{~b}$ & $0,73 \mathrm{c}$ \\
\hline Aramo + Dash & tepraloxydim +Dash & $80+1,0$ & $0,4+1,0$ & $0,70 \mathrm{~b}$ & $0,91 \mathrm{~b}$ & $0,46 b$ & $0,47 \mathrm{c}$ \\
\hline Aramo + Dash & tepraloxydim +Dash & $160+1,0$ & $0,8+1,0$ & $0,60 \mathrm{~b}$ & $0,49 \mathrm{~b}$ & $0,21 \mathrm{~b}$ & $0,50 \mathrm{c}$ \\
\hline Aramo + Dash & tepraloxydim +Dash & $240+1,0$ & $1,2+1,0$ & $0,53 \mathrm{~b}$ & $0,66 \mathrm{~b}$ & $0,31 b$ & $0,49 c$ \\
\hline Aramo + Dash & tepraloxydim +Dash & $320+1,0$ & $1,6+1,0$ & $0,71 \mathrm{~b}$ & $0,53 \mathrm{~b}$ & $0,13 \mathrm{~b}$ & $0,34 \mathrm{c}$ \\
\hline Poast + Assist & sethoxydim + Assist & $230+1,0$ & $1,25+1,0$ & $0,51 \mathrm{~b}$ & $5,16 a$ & $0,28 b$ & $7,35 \mathrm{a}$ \\
\hline Poast + Assist & sethoxydim + Assist & $460+1,0$ & $2,5+1,0$ & $0,43 \mathrm{~b}$ & $4,45 \mathrm{a}$ & - & - \\
\hline Poast + Assist & sethoxydim + Assist & $920+1,0$ & $5,0+1,0$ & -- & - & $0,22 \mathrm{~b}$ & $3,88 \mathrm{~b}$ \\
\hline Testemunha & - & - & - & $2,52 \mathrm{a}$ & $5,21 \mathrm{a}$ & $7,04 \mathrm{a}$ & $7,34 \mathrm{a}$ \\
\hline $\begin{array}{l}\mathrm{F} \\
\mathrm{CV} \\
\text { DMS 5\% }\end{array}$ & & & & $\begin{array}{r}2,18 \\
39,37 \\
0,47\end{array}$ & $\begin{array}{r}40,88 \\
36,27 \\
1,33\end{array}$ & $\begin{array}{c}2,596 \\
46,31 \\
0,380\end{array}$ & $\begin{array}{c}52,719 \\
44,75 \\
1,866\end{array}$ \\
\hline
\end{tabular}

${ }^{1 /}$ Médias seguidas da mesma letra na coluna não diferem entre si a $5 \%$ pelo teste de Tukey.

As principais diferenças, do primeiro para o segundo experimento, foram a dose de sethoxydim, que passou de 2 para $4 \mathrm{~L} \mathrm{ha}^{-1}$, a manutenção dos vasos fora da casa de vegetação e o estádio de desenvolvimento no momento da aplicação. Apesar disso, os resultados seguiram o mesmo padrão que os encontrados no primeiro experimento. Os níveis de controle das plantas foram elevados em todos os produtos no biótipo suscetivel e, no resistente, apenas para clethodim e tepraloxydim (Tabela 3). Para estes dois produtos a diferença de controle não ultrapassou 3\%. A biomassa seca das plantas obtida confirma as avaliações visuais (Tabela 4).

Cortez (2000) encontrou diferenças de controle ao estudar a resistência de capimmarmelada aos inibidores da enzima ACCase. Em revisão bibliográfica, esse autor cita os trabalhos de Devine \& Shimabukuro, os quais afirmam que as variações na sensibilidade são atribuídas a mais de uma alteração no mecanismo de resistência prevalecente nas espécies. Ainda segundo Cortez (2000), a resistência aos inibidores da enzima ACCase ocorre devido à mutação, que a torna insensível a herbicidas. A variabilidade na resistência pode ser explicada pela possibilidade de ocorrer mutação em diferentes locais do gene codificador da ACCase.
Os resultados permitem afirmar que o biótipo BRAPL-1.02, embora tenha manifestado resistência ao herbicida sethoxydim, foi controlado pelos produtos clethodim e tepraloxydim. Convém alertar, porém, que outros biótipos podem não mostrar o mesmo comportamento.

\section{LITERATURA CITADA}

CHRISTOFFOLETI, P. J. et al. Imidazolinone resistent Bidens pilosa biotypes in Brazilian soybean areas. In: MEETING OF THE WEED SCIENCE SOCIETY OF AMERICA, 36., 1996. Norfolk. Abstracts... Champaign: WSSA, 1996. p. 10.

CORTEZ, M. G. Resistência de biótipos de Brachiaria plantaginea (Link) Hitchc. A herbicidas inibidores da Acetil Coenzima A Carboxilase. 2000. 214 f. Tese (Doutorado em Agronomia) - Escola Superior de Agricultura "Luiz de Queiroz", Piracicaba, 2000.

EMBRAPA SOJA. Tecnologias de produção de soja Paraná - 2004. Londrina: 2003. 218 p.

GAZZIERO, D. L. P. et al. Resistência de amendoim-bravo aos herbicidas inibidores da enzima ALS. Planta Daninha, v. 16, p. 118-125, 1998.

GAZZIERO, D. L. P. et al. Resistência da planta daninha capim-marmelada (Brachiaria plantaginea) aos herbicidas inibidores da enzima ACCase na cultura da soja. Planta Daninha, v. 18, n. 1, p. 169-180, 2000.

Planta Daninha, Viçosa-MG, v. 22, n. 3, p. 397-402, 2004 
GAZZIERO, D. L. P. et al. Resistência de biótipos de Brachiaria plantaginea aos herbicidas inibidores da ACCase aplicados em soja. In: CONGRESSO BRASILEIRO DA CIÊNCIA DAS PLANTAS DANINHAS, Caxambu. Resumos... Caxambu: SBCPD, 1997. p. 88.

PONCHIO, J. A. R. et al. ALS enzyme assay from Bidens pilosa biotypes of the Brazilian soybean areas to determine the sensitive to imidazolinone and sulfonilurea herbicides. In: MEETING OF THE WEED SCIENCE SOCIETY OF AMERICA, 36., 1996, Norfolk. Abstracts... Champaign: WSSA, 1996. p. 79.
SOCIEDADE BRASILEIRA DA CIÊNCIA DAS PLANTAS DANINHAS - SBCPD. COMITÊ BRASILEIRO DE RESISTÊNCIA DE PLANTAS AOS HERBICIDAS.

Identificação e manejo de plantas daninhas resistentes aos herbicidas. Londrina: 2000. 32 p.

VIDAL, R. A.; FLECK, N. G. Three weed species with confirmed resistance to herbicides in Brazil. In: MEETING OF THE WEED SCIENCE SOCIETY OF AMERICA, 37., 1997, Orlando. Abstracts... Orlando: 1997.

WEED SCIENCE SOCIETY OF AMERICA. Disponível em: <www.weedscience.org>. Acesso em: 30 abr. 2004. 